unaware of its existence until it appeared-a week after my own report.

In other words, I'm afraid, Now!, quite legitimately, "scooped" the Lancet on its own territory on this occasion. Although it verges on pedantry to expect a lay publication like Now! to be as scrupulous as a relatively academic journal such as the $B M F$ in quoting recondite sources, I entirely agree that sources should be quoted. We will always give credit where it is due, and I hope the $B M \mathcal{F}$ will try harder in future to do the same.

DAvid Loshak Science Editor,
Now! Magazine

London EC1

\section{Congenital varicella}

SIR,-It was interesting to read in Professor A P Waterson's article (8 September, p 564) of the relatively few case reports of congenital abnormalities associated with intrauterine varicella infection. Probably more cases have occurred but not reached the literature.

Three cases of varicella have occurred among pregnant patients booked in this clinic since 1977 . In two cases the mothers were affected at 29 and 31 weeks respectively: in both cases the rash and symptoms were mild. No untoward features occurred during the rest of the pregnancies and the infants did not show any clinical signs of infection at birth. Virus was not isolated from the infants unfortunately $\operatorname{IgM}$ assays and complement fixation tests were not performed.

The third patient was affected earlier in pregnancy, the rash, which was extensive, appearing during the 16 th and 17 th weeks. The infection was confirmed both clinically and by complement fixation test. Acute polyhydramnios and pre-eclampsia were additional complications to this pregnancy from the 31 st week. Ultrasonic assessment at this time suggested the presence of a meningocele and a neurogenic bladder. Labour was induced in the 36th week after prolonged hospitalisation and amniocentesis to relieve the polyhydramnios. A live girl was delivered weighing $2 \cdot 4 \mathrm{~kg}$ (15th-20th percentile for gestational dates), and she remained unconscious throughout her life of 36 hours. She was noted to have a dilated left pupil and a large transparent skin defect above the right iliac crest extending towards the lumbar region. A similar lesion was seen in front of the left ear. There was a flaccid paralysis of the left arm.

Necropsy did not reveal any skeletal abnormalities, and the brain convolutions appeared to be normal. The abnormalities present were an atresia of the sigmoid colon at its junction with the rectum an enlarged bladder with a hypertrophic muscle wall, and a vesicourethral fusion defect with the bladder neck exiting into the vagina. The liver was studded on its surface and internally with hard, yellow nodules measuring about $0.5 \mathrm{~mm}$ in diameter. The abdominal surface of the diaphragm showed many similar lesions and histological examination indicated that these were calcified deposits. The lungs, liver, and spleen showed widespread infiltrative lesions consistent with varicella infection when examined microscopically. Clearly this infant had been subjected to extensive systemic viral effects, the remains of which could be detected in many organs. Possibly the suspected "meningocele" was a large bullous eruption which resulted in the skin defect seen at birth.

The effects of varicella on the fetus are variable and the results of pregnancies affected by this virus are awaited with interest by the clinicians involved and with apprehension by the expectant parents. With our present state of knowledge we can only reassure our patients that abnormalities are "unlikely" and hope that time proves us correct. For this reason it is to be hoped that those who have records of similar cases or subsequently encounter them will make the effort to report them and include details of the duration of pregnancy at the time of the eruption, the severity of maternal symptoms, the further progress of the pregnancy, and the presence or absence of obvious effects on the infant. Unfortunately the recording system of the Office of Population, Censuses and Surveys does not correlate congenital abnormalities with probable aetiological factors, so that retrospective analysis at this level is not possible.

Louise Margaret Maternity Hospital,

IAN ALEXANDER Aldershot, Hants

\section{The premature breech}

SIR,-I read with interest the letter by $\mathrm{Mr}$ J P Calvert (28 July, p 274) advocating the use of the classical caesarean section in some cases of the premature breech.

I agree that the transverse lower segment incision for caesarean section in the premature breech can be hazardous owing to possible entrapment of the fetal head. But the classical caesarean section scar may increase the risk of maternal and perinatal morbidity and mortality owing to scar rupture. ${ }^{12}$ Weakening of the scar may occur during involution of the uterus, and increase in intrauterine pressure during Braxton Hicks's contractions may cause rupture in the next pregnancy.

I would therefore also consider the vertical incision in the lower segment as described by De Lee. ${ }^{3}$ It is possible to make this incision if the lower segment has been stretched sufficiently by active labour. The advantage of the De Lee's incision is that it can be easily extended into the upper uterine segment, and this may occasionally be necessary to allow easy delivery of the aftercoming head.

M ST C HOPPER

St Mary's Hospital,

${ }^{1}$ Myerscough, P R, Munro Kerr's Operative Obstetrics, 9th edn, p 515. London, Ballière Tindall, 1977. Dewhurst, C J, fournal of Obstetrics and Gynaec
of the British Commonwealth, 1957, 64, 113. of the British Commonwealth, 1957, 64, 113 . Medical Association, 1919, 73, 91 .

\section{Antenatal prediction of sex}

SIR,-The report by Dr A J Williams (29 September, p 767) and leading article (p 754) on antenatal prediction of sex quite rightly warn of the pitfalls in predicting the phenotypic sex of an infant based on chromosome analysis of cultured aminotic fluid cells.

No mention was made of the use of amniotic fluid steroid measurements to determine the sex of the fetus. Several workers have reported that amniotic fluid concentrations of testosterone are significantly higher during the second trimester of pregnancies associated with a male fetus. ${ }^{1-4}$ Presumably the same would apply to a $46, \mathrm{XY}$ fetus with normal testosterone biosynthesis but end-orgon unresponsiveness to adrogens (testiculer feminization syndrome). Defects in testosterone biosynthesis and XY gonadal dysgenesis would be associated with amniotic fluid testosterone concentrations appropriate for a female fetus.

The case report by $\mathrm{Dr}$ Williams serves to emphasise that parents should be made aware that knowledge of the fetal sex chromosome complement would not necessarily predict correctly the sex of the infant should there be a disorder of sex differentiation present.

I A Hughes

K M LAURENCE

Department of Child Health, Wepartment of Child Health,
Cardiff CF4 4XN

1 Doerner, G, et al, Endokrinologie, 1973, 61, 317

2 Giles, H R, et al, Gynecologic Investigation, 1974, 5, 317 .
${ }^{3}$ Warne, G L, et al, fournal of Clinical Endocrinology and Metabolism, 1977, 44, 934 . Zondek, L H, Zondek, T, and Mansfield, M, British
Medical fournal, 1979, 1, 341 .

\section{Beta-blocker withdrawal syndrome}

SIR,-We are interested by the letter from $\mathrm{Dr}$ $\mathrm{M} \mathrm{J}$ Lewis and his colleagues (8 September, p 606) commenting on our paper about the beta-blocker withdrawal syndrome (11 August, p 366). Many explanations have been offered for the worsening of angina pectoris when the beta-blockers are suddenly withdrawn, including progression of the disease, adaptation to a greater level of physical activity during beta-blockade, etc. Two explanations have been proposed which might involve the sympathetic nervous system directly in a rebound phenomenon-increased release of noradrenaline from adrenergic nerves to the heart and hypersensitivity of the cardiac $\beta$ receptors.

We investigated patients up to four days after sudden cessation of treatment with propranolol to see whether there was increased sympathetic activity analogous to that which occurs after withdrawal of clonidine and other imidazoline-like compounds which have an $\alpha$ receptor agonist action in the central nervous system. During treatment with propranolol there is a moderate increase in plasma noradrenaline, which probably reflects increased activity of the baroreflex consequent on the reduction in the cardiac output. Using a sensitive and specific radioenzymatic assay, we found a smooth decline in the plasma noradrenaline to normal when propranolol was stopped. Nattel et $a l^{1}$, who used a less specific assay for total plasma catecholamines, found a similar pattern, although the time the catecholamines took to fall was slightly longer in their study. Thus it is common ground that there is not a sudden overshoot of sympathetic activity on cessation of treatment with propranolol

The second possibility concerns supersensitivity of cardiac $\beta$-receptors after a long period of competitive receptor blockade. Nattel et $a l^{1}$ used isoprenaline dose-response curves to study this situation and found a moderate increase in response between the fourth and ninth day after withdrawal. We understand from conversations with $\operatorname{Dr} R \mathrm{E}$ Rangno of this group that they have recently shown a similar phenomenon after cessation of treatment with metoprolol, although the period of hypersensitivity was shorter. The observations made by Ross and his colleagues ${ }^{2}$ are consistent with this explanation.

It is, however, important not to overstate the magnitude of the hypersensitivity. On average it amounted to about a twofold shift in the isoprenaline dose-response curve in the study by Nattel et al. One patient showed a fivefold increase in sensitivity to isoprenaline but this was at only one observation point and might have been a random fluctuation. If a twofold increase in receptor sensitivity is 
equated with physiological activity that would cause a twofold increase in noradrenaline release it is roughly equivalent to a patient standing for five minutes after lying down for ten. It is not reasonable to compare this situation with a catecholamine cardiomyopathy induced by very large doses of $\beta$-receptor agonists in animals or, as is sometimes seen, in patients with phaeochromocytoma.

There is one other interesting implication, which was pointed out recently by $\mathrm{Dr}$ Rangno at a meeting in the Hague. The small degree of receptor hypersensitivity after withdrawal can be blocked by a very small dose of a $\beta$ receptor blocking agent. Thus a graded reduction in dose of the $\beta$-adrenergic blocker is not required; but a sudden reduction to a very small dose-that is, propranolol 10-20 $\mathrm{mg} /$ day - should be quite safe so long as this dose is continued for about two weeks before it is finally stopped.

C T DOLLERY

T J B MALING

Royal Postgraduate Medical School, Hammersmith Hospital,

London W12 OHS

${ }^{1}$ Nattel, S, Rangno, R E, and Van Loon, G, Circulation

1979 , 59, 1158.
${ }^{2}$ Ross, P J, Lewis, M J, and Henderson, A H, British Medical fournal, 1975, 1, 875.

\section{Vitamin $B_{12}$ : an area of darkness}

SIR,-We agree with Dr C W Picard (6 October, p 867) that there were some who doubted the predominant role of cyanocobalamin in metabolism as early as the 1950 s. Nevertheless, for many years it was very widely assumed that cyanocobalamin was the main form of vitamin $B_{12}$ in the body, and we do not think our review falsified the general picture.

D M Matthews

J LINNELL

Vincent Square Laboratories, Westminster Hospital,

\section{Life-threatening arrhythmias and} intravenous cimetidine

SIR,-In a recent paper (29 September, p 768) Dr J Cohen and others described the serious cardiovascular complications that occur during treatment with intravenous cimetidine. I would like to suggest that hyoscine butylbromide (Buscopan) can prevent these arrhythmias.

Hyoscine butylbromide has been shown to suppress the oculocardiac reflex during operations for correction of squint. ${ }^{1}$ During a current study designed to show that it has as effective though briefer chronotropic and inotropic actions on the heart during general anaesthesia as intravenous atropine, it was noticed that hyoscine butylbromide has an antiarrhythmic action. Not only did it not cause arrhythmias as atropine can but it restored sinus rhythm for periods of up to one hour to hearts affected by arrhythmias associated with pancuronium and halothane. Among the 44 cases so far studied hyoscine butylbromide restored normal cardiac rhythm in two cases of nodal bradycardia and hypotension, in three cases of multiple ventricular extrasystoles, and in one case of auriculoventricular dissociation within one minute of intravenous injection.

Like Dr Cohen, I can only speculate about an evident temporal association; unlike him I cannot offer even one hypothesis to explain my observations. However, the similarity between the arrhythmias following intravenous cimetidine and those associated with the oculocardiac reflex - that is, bradycardia with hypotension, a trioventricular dissociation, and asystolic cardiac arrest-suggests that a drug that can control one would also control the other.

Department of Anaesthesia,

North Tees General Hospita

Stockton-on-Tees, Cleveland TS19 8PE

${ }^{1}$ Fry, E N S, and Hall-Parker, B J P, British fournal of Ophthalmology, 1975, 59, 525 .

\section{Day-bed units}

SIR,-We were interested to read the report "Operations for hernia and varicose veins in a day-bed unit" from $\mathrm{Mr} \mathrm{C} \mathrm{V}$ Ruckley (22 September, $p$ 712) and we would support his enthusiasm for short-stay care. One could, however, be misled by the title into assuming that the majority of varicose veins were being treated by day care, but analysis of their data shows a small decline in such management over the last five years.

The authors are correct in stating that "it would not be right to claim efficiency in health care without taking account of the views of patients." We carried out a survey in 1978 of the Hammersmith Hospital experience in day surgery for varicose veins in which we sought the patient's opinion. ${ }^{1}$ This showed that patients did not like day-care vein surgery when more than one incision was necessary. An increased number of general practitioner call-outs, unacceptable analgesia consumption, etc, accompanied multiple skin incisions and our practice was modified accordinglyespecially the ending of the long saphenous strip on a day-care basis.

If one accepts that the success of a varicose vein operation can be directly related to the extent of surgery then day-care surgery will often provide inadequate treatment alone.

\section{Charles Clyne}

University Department of Surgery, Southampton

Hammersmith Hospital,

London W12 0HS

Clyne, C A C, and Jamieson, C W, British fournal of Surgery, 1978, 65, 194.

SIR,-I was interested in the experiences of Dr J B Rainey and Mr C V Ruckley in the Edinburgh day-bed unit (22 September, p 714). I recently spent 18 months as an obstetric and gynaecological resident in Canada, where day beds are widely used. All our patients having minor gynaecological procedures and laparoscopies were admitted as day patients unless medically unsuitable.

Admittedly we did not have a waiting list problem, most patients being admitted within a month. When the decision that surgery was indicated was made in the clinic the patient's medical status was assessed, with examination of respiratory and cardiovascular systems and routine blood tests. When the patient arrived in the gynaecological day ward routine observations were made by the sister and she was seen by the doctor only when she arrived in theatre and again prior to discharge.

This system not only eased the bed situation but also avoided the need for junior doctors to hurriedly requestion and re-examine several patients each morning before rushing off to theatre. I feel that with our ever-increasing waiting lists and work load day beds should be used wherever facilities permit.

DEBORAH MONCRIEFF

Churchill Hospital,

Smoking and acclimatisation to altitude

SIR,-Dr N MacLean's suggestion (29 September, p 799) that to starve Olympic athletes of oxygen by controlled smoking and so "acclimatise" them in the same way that altitude training does is ingenious but does not really follow from his observations of mountain sickness in himself and fellow climbers. Acute mountain sickness cannot be caused solely by induced alveolar hypoxia; if it were, asthmatics would exhibit the symptoms during prolonged attacks (which they don't) and the condition occurring at altitude would be alleviated by oxygen (which it isn't). ${ }^{1}$

From my own observations of some hundreds of sea-level residents ascending to and living at $3000-4200 \mathrm{~m}$ in the Andes, I can say that smoking habits have no effect on susceptibility to mountain sickness. Neither would one expect them to have any effect, as they are overwhelmed by other, more important factors such as exertion and, not least, a huge individual variation in response. Whether artificial" acclimatisation by smoking" followed by abstinence prior to athletic endeavour could improve total aerobic capacity at sea level (or high altitude) in the -medium term is quite another question, albeit of theoretical interest.

Whatever the answer (and there must be less deleterious ways of incurring reversible hypoxia-daily suffocation with a pair of running shorts, for example), acute mountain sickness has a more complex aetiology than suggested and the likelihood of its development in an individual is no guide to his future acclimatisation and physical performance at high altitude.

Olney, Bucks

David SNashall 'Ward, M, Mountain Medicine: A Clinical Study of
Cold and High Altitude, p 266. London, Crosby,

\section{Wanted: a new wound dressing}

SIR, - We would agree with your leading article (22 September, p 689) that wound dressings in common use are less than ideal, and welcome the attention drawn to Turner's comprehensive review. ${ }^{1}$ We would also agree with the properties suggested as necessary for an ideal dressing, but are surprised that no mention is made of the use of the silicone foam elastomers, which fully meet these requirements in relation to granulating wounds.

This material, developed as a wound dressing in Cardiff, is contour forming, soft, resilient, absorbent and non-adherent. We first reported the use of silastic foam dressing Q7-9100 (Dow Corning Ltd) in $1974^{23}$ and experience in this department now covers over 1000 patients treated for a wide variety of types of granulating wounds, including pilonidal sinus, infected abdominal wounds, sacral pressure sores, and anal and perineal wounds, skin graft donor sites, and varicose ulcers. 